\title{
CÓMO DESAPARECER DEL MAPA: UN CASO PRÁCTICO DE DISIDENCIA ONLINE
}

\author{
Sergio Luna Lozano \\ Universidad Miguel Hernández de Elche \\ Yasmina Morán Conesa \\ Universitat Politècnica de València
}

\section{Resumen}

La red Internet ha pasado de ser un lugar de posibilidades emancipatorias que permitió la aparición de espacios de actuación independientes, a un espacio hiperregulado por grandes compañías. Esta transformación también ha afectado a las prácticas artísticas relacionadas con Internet, que han evolucionado de explorar el potencial de Internet como medio de creación y lugar de resistencia a reflexionar sobre la propia red y sus mecanismos. A partir de un caso práctico, el artículo analiza las posibilidades de disidencia desde las prácticas artísticas en el entorno actual de Internet y las herramientas comerciales de la compañía Google, y más concretamente en el servicio Google Street View.

Palabras clave: GOOGLE STREET VIEW; ARTE POSTMEDIA; INTERNET; POST-INTERNET, ANONIMATO.

\section{HOW TO DISAPPEAR FROM THE MAP: A PRACTICAL CASE OF ONLINE DISSIDENCE}

\section{Abstract}

The Internet network has changed from being a place of emancipatory possibilities which allowed the emergency of independent spaces, to a space that is highly regulated by big companies. This transformation has also affected those art practices related to the Internet, which have evolved from exploring the potential of the net as a means of creation and as a resistance area, to reflect on the net itself and its mechanisms. From a study case, this article analyzes the plausibility of dissidence of the artistic practices from the current environment of the Internet and Google's commercial tools, more specifically the service Google Street View. Keywords: GOOGLE STREET VIEW; POSTMEDIA ART; INTERNET;
POST-INTERNET; ANONYMITY

Luna Lozano, Sergio \& Yasmina Morán Conesa. 2018. "Cómo desaparecer del mapa: Un caso práctico de disidencia online”. AusArt 6(2): 9-21. DOI:10.1387/ausart.20381

\section{AUSART}




\section{EL CAMBIO DE PARADIGMA DEL PRIMER INTERNET}

El advenimiento de la web 2.0 a principios de la década de los 2000 traía consigo toda una serie de novedades que rescataban a la industria empresarial asociada a Internet del estallido de la crisis de las puntocom. Estos cambios se fundamentaban principalmente en una transformación de paradigma en la lógica de la web comercial, hasta entonces basada principalmente en la creación de grandes portales que constituían enormes fuentes de información generadas por los equipos profesionales de las propias empresas (Martín Prada 2012, 29), y entornos web unidireccionales donde el usuario se situaba como un simple consumidor de información.

Pero antes del estallido de las puntocom no sólo existía la realidad de los intereses privados en Internet. Todo lo contrario: otras esferas colonizaron la red, existiendo "una segmentación entre el mundo institucional, la esfera política, los intereses corporativos, los intereses privados y la contracultura" (Gianetti 2003), compartiendo todos una postura optimista sobre la red.

Desde dicha contracultura, y más concretamente desde el activismo y arte, se defendió la red como espacio de libertad y activismo, mediante manifiestos como la "Declaración de independencia del ciberespacio" (1996) de Electronic Frontier foundation, prácticas de deconstrucción de Internet, por artistas como Jodi o Vuk Cosic, o proyectos activistas o hacktivistas como los de Critical Art Ensemble o Electronic Disturbance Theater, que promovían un posicionamiento crítico a la web comercial mediante la 'desobediencia civil electrónica', la que llevaban a cabo mediante acciones abiertamente ciberactivistas.

Por su parte, los usuarios, que no sólo querían recibir información, sino que querían poseerla y distribuirla, venían organizándose en movimientos y comunidades como el software libre o posteriormente la cultura libre. Gracias a la interoperabilidad de la web 2.0 , la red permitió la creación de redes abiertas y cooperativas, en las que los usuarios se convertían en los productores y a la que se atribuyó no sin motivo, "de una impredecible fuerza política" (Brea 2007,30 ) que parecía capaz de cumplir lo sueños utópicos de la emancipación a través de la técnica. Además, existió toda una proliferación de usos comunicativos y subjetivos de la red: no sólo la efectividad de la trasmisión de conocimiento, los individuos buscaron la afectividad allí donde la encontraron. 
Las empresas no tardaron en vislumbrar el potencial económico de toda esta materia bruta, y sólo aquellas empresas que suministraron herramientas para que los usuarios produjeran contenidos y relaciones son las que se mantuvieron en primera línea del negocio de la red. A partir de entonces, será el usuario de estos portales el "proveedor de los contenidos del sitio que visita" (Martín Prada 2012, 29), constituyéndose de este modo los portales web como espacios de participación entre los usuarios, que abastecerán de información a las empresas que gestionan estos entornos y dotarán de contenido a los mismos; una deriva que generó que las empresas se enfocaran ya no a producir contenido, sino a desarrollar herramientas donde los usuarios pudieran gestionar la información y crear los contenidos por sí mismos, a la vez que se originaban espacios que permitían la interacción comunicativa del usuario en las primeras redes sociales.

Esta transformación, por tanto, simplificó el acceso de los internautas a la creación de espacios web a través de múltiples plataformas donde discutir y compartir contenidos, convirtiendo al usuario en un sujeto activo, pero por otra parte, también repercutió en una "tendencia hacia el control oligopolístico del uso de Internet" y "una proliferación de plataformas centralizadas" (Martín Prada 2012, 26) que con el transcurso del tiempo han ido monopolizando la red, en un paso lógico e implacable del capitalismo hacia una nueva economía de lo simbólico, "sin mercancías" (Brea 2007, 25) en el que "la producción ha expandido su campo para abarcar todas las modalidades de actividad -o pasionalidad-que conciernen a lo humano" (Brea 2007, 35).

\section{EL CONTROL COMERCIAL DE INTERNET Y LA RESPUESTA DE LA PRÁCTICA ARTÍSTICA}

De entre todas las compañías emergentes en el inicio de la web 2.0, las empresas que sostuvieron su modelo de negocio en la oferta de servicios gratuitos como medio de conseguir volumen de usuarios y tráfico de los que extraer información comercial, son las que prosperaron. La extracción de datos aprovecha toda una serie de variables que abarcan desde el uso de las referencias personales aportadas por los usuarios, hasta los datos que la propia plataforma obtiene por su particular mecanismo de funcionamiento. Estas compañías percibieron que toda la experiencia dentro de sus aplicaciones puede ser 'datificada' y por tanto, comercializada. 
Sin duda, una de estas compañías que mayor tráfico de Internet controla es Google, que junto a Facebook, constituyen dos de los gigantes tecnológicos con más dominio en la red, estimándose una influencia directa en más del $70 \%$ del tráfico de Internet (Staltz 2017), y provocando que, lo que hace unos años suponía una red más diversa donde las grandes compañías competían entre ellas, actualmente se hayan centrado en cubrir y defender su parcela de especialización; de este modo, Google se ha convertido en la compañía de Internet de conocimiento y Facebook en la compañía de Internet social (Staltz, 2017).

Los intereses de la práctica artística en la red en los últimos años han evolucionado de explorar "las posibilidades específicas que ofrecía Internet como nuevo medio para la creación artística" (Martín Prada 2012, 6) a reflexionar 'acerca de' o ‘sobre' Internet” (Martín Prada 2012, 6). En este contexto, Google o Facebook no solamente se han posicionado como compañías que controlan la red, sino que además suponen instrumentos de creación donde a través de sus tecnologías y servicios, han ejercido una gran influencia en la práctica artística contemporánea. Plataformas como Google Imágenes, YouTube, Google Maps, Facebook o Twitter, constituyen un conjunto de herramientas que sirven de origen para distintos trabajos artísticos que se vienen realizando desde múltiples enfoques. Muchos de estos trabajos se han centrado en evidenciar los errores y mecanismos de los servicios de las grandes compañías que operan en la red desde una perspectiva -en su mayor parte- crítica e irónica, a través de una serie de intervenciones que aprovechan pequeñas fisuras en dichas plataformas; acciones estas que, la mayoría de las veces, entendemos que suponen la única forma posible de disidir ante la imposibilidad de intervenir en un sistema -el de Internet- tan excesivamente controlado y hermético.

\section{GOOGLE STREET VIEW COMO HERRAMIENTA}

Una de las plataformas más emblemáticas que sirve a la vez como espacio de intervención y herramienta de producción es Google Street View, el popular servicio de Google Maps, que se ha consolidado como la plataforma de vistas a pie de calle más utilizada desde que se introdujera por primera vez en Estados Unidos en 2007. El objetivo principal de Street View es ofrecer a sus usuarios vistas panorámicas de 360 grados de una gran parte del mundo, explorando el territorio a través del desarrollo de una gama de dispo- 
sitivos equipados con cámaras que posibilitan el registro de diversos lugares: coches que circulan por calles y caminos, mochilas que permiten mapear a pie sitios de difícil acceso, carros para registrar interiores de edificios, triciclos con los que se puede explorar calles y espacios por donde no puede acceder un coche, e incluso motos de nieve que cartografían pistas de esquí y sus alrededores. Esta variedad en la flota de exploración incide en el deseo de Google de llegar hasta el último rincón del planeta, a la vez que conecta con una antigua inquietud que ha obsesionado a cualquier proyecto de mapeo, y que consiste en cartografiar un terreno hasta que el mapa en sí mismo se convierta en un territorio por derecho propio (Vavarella 2013); un mapa, que tal y como imaginase Borges en un breve cuento atribuido a un supuesto Suárez Miranda ${ }^{1}$, llegue a tener el mismo tamaño del lugar que representa:

En aquel Imperio, el arte de la cartografía logró tal perfección que el mapa de una sola provincia ocupaba toda una ciudad, y el mapa del imperio, toda una provincia. Con el tiempo, estos mapas desmesurados no satisficieron y los colegios de cartógrafos levantaron un mapa del imperio, que tenía el tamaño del imperio y coincidía puntualmente con él.

(Borges [1935] 1987, 136)

En este sentido, se puede entender que la representación de la realidad a través de Internet ha alcanzado tal nivel de semejanza, que "supone un duplicado de la realidad en la medida en que suplanta nuestra percepción directa del mundo" (Fontcuberta 2016, 44) o, también podríamos decir, que en caso de Street View, lo aparente reemplaza a lo tangible, lo que convierte al usuario en un flâneur virtual o -como sugiere el artista Emilio Vavarella (2013) - un media-flâneur, donde el individuo no vagabundea entre las calles y la arquitectura de la ciudad, sino que su paseo es el producto de nuevos movimientos digitales a través de arquitecturas de software, autopistas de información, montones de datos e interfaces híbridas. El deambular por Google Street View se ha convertido, por lo tanto, en una acción que toma el relevo o, mejor dicho, continúa con "la historia del andar como forma de intervención urbana" (Careri $2002,21)$, una práctica recurrente en el ámbito artístico que comienza con el dadaísmo alrededor de 1921.

De este modo, desde la que se puede considerar como la primera intervención artística en la plataforma realizada por los artistas Ben Kinsley y Robin Hewlett con Street with a View $(2008)^{2}$, son numerosos los proyectos ejecutados a partir del famoso servicio de Google. Trabajos como 9-eyes (2008 - actualidad) de Jon Rafman ${ }^{3}$, The Google Trilogy (que incluye Report a Problem, Michele's 
Story y The Driver and the Cameras, 2012) ${ }^{4}$ de Emilio Vavarella, Street Ghosts (2012 - 2017) $)^{5}$ de Paolo Cirio, Anonymous Gods (2014) ${ }^{6}$ de Marion Balac o Trolling Google Art Project (2013 - actualidad) ${ }^{7}$ de Mario Santamaría -entre otros muchos-, convierten a los artistas en rastreadores en busca de imágenes que visibilizan los errores de la tecnología cuasi perfecta de Google, que en parte se deben a los automatismos que rigen el proceso de mapeado y procesado de las imágenes que escapan al control humano; en otras ocasiones ciertos proyectos se centran en rescatar imágenes captadas de forma involuntaria por los dispositivos de los vehículos de Google y que muestran curiosas escenas de la vida cotidiana, en un ejercicio de renovación del famoso "instante

\section{Google Maps}

Informar acerca de una imagen inadecuada de Street View.

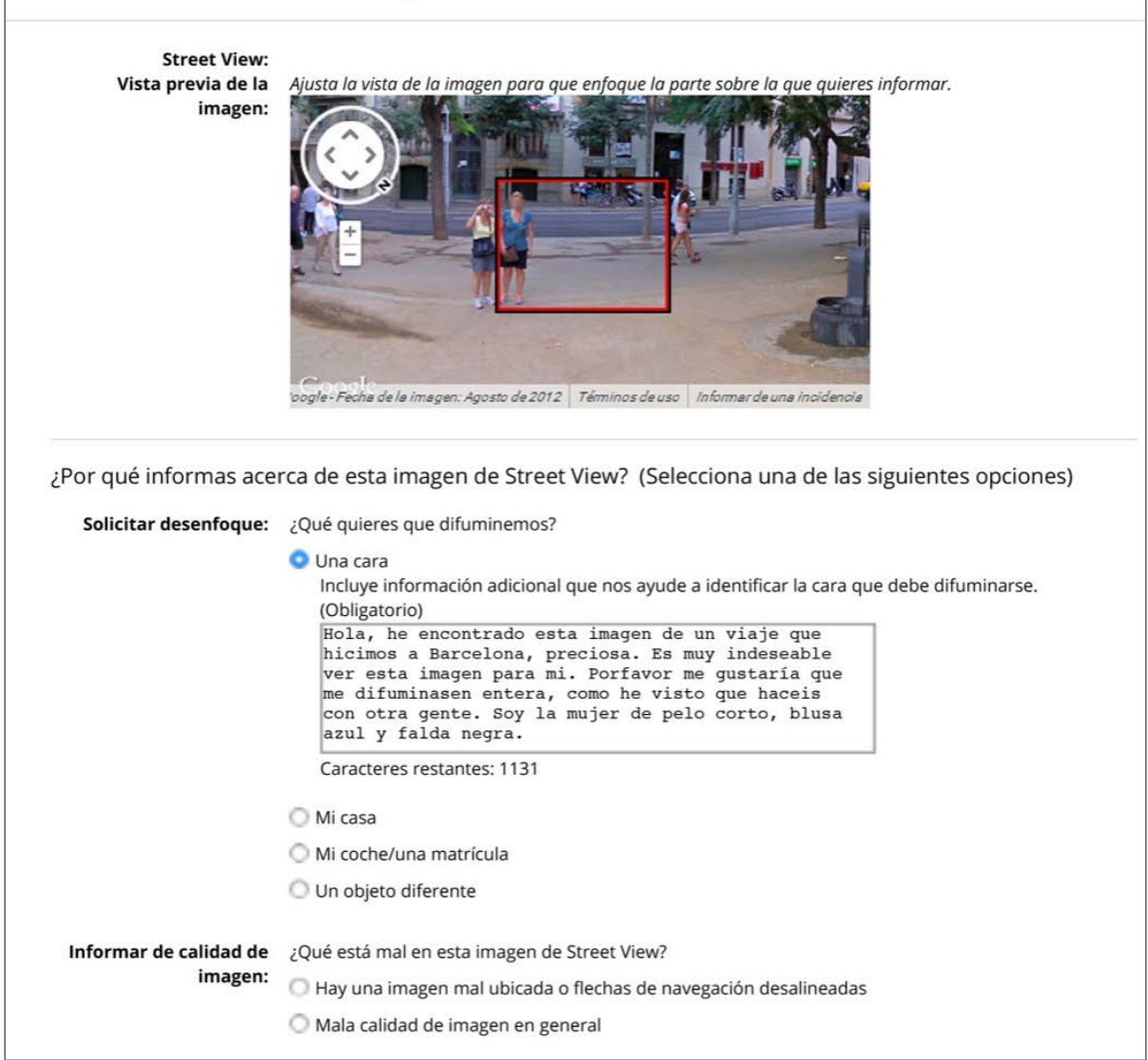

Fig.1 Detalle de formulario utilizado en una de las intervenciones. 
decisivo" de Cartier-Bresson; desde otros planteamientos, se intenta reflejar la relación entre el individuo y los sistemas de poder que imperan en Internet, profundizando en la correspondencia entre la realidad física y la virtual. En cualquier caso, son pocos los proyectos que consiguen realizar una intervención en el sentido de "modificar el espacio" virtual. La mayoría de los trabajos apuntan a la vía de la búsqueda de imágenes, recolección y su posterior clasificación: accidentes de tráfico o catástrofes naturales, glitchs y errores de procesamiento, reflejos que muestran los dispositivos ópticos de Google, estatuas desenfocadas debido a que el sistema las identifica como rostros humanos o imágenes que muestran los límites del territorio explorado, es decir, aquel punto donde los vehículos de la compañía no han podido acceder.

\section{EL CASO DE OUT OF FOCUS}

A partir de esta premisa -la de alterar de algún modo el entorno virtual de Street View-, en 2014 comenzamos a realizar el proyecto Out of Focus, un trabajo basado en una serie de intervenciones realizadas sobre la plataforma de Google, que principalmente consistía en modificar diversos elementos de su entorno. Así, a través de un formulario de contacto que Google proporciona a sus usuarios para pedir difuminar las vistas de su cara, vehículo o casa (el formulario "informar de un error") (Fig. 1), se difuminaron numerosos elementos mediante falsas identidades e historias ficticias. Lo notable de estos elementos alterados, es que se encuentran permanentemente difuminados en las vistas correspondientes de Google Street View, y el tiempo que estas intervenciones permanezcan visibles dependerá de la capacidad de refresco de la plataforma, esto es, del tiempo que pueda tardar la compañía en volver a fotografiar y mapear los lugares de las imágenes intervenidas, pasando así a formar parte del pasado virtual de las vistas de Street View ${ }^{8}$.

El proyecto se materializó por medio de una serie de veinticinco fotografías que se entienden como el resultado físico de las intervenciones ${ }^{9}$, donde el título de cada fotografía se corresponde con la URL de la propia intervención a la que se refiere (Fig. 2 y 3). De este modo, las obras de este proyecto adquieren una doble entidad: por un lado, la propia fotografía como objeto artístico, y por otro la intervención que puede ser consultada a través de la URL mencionada o visualizada por cualquier usuario que explore por casualidad en Google Street View estos lugares. 


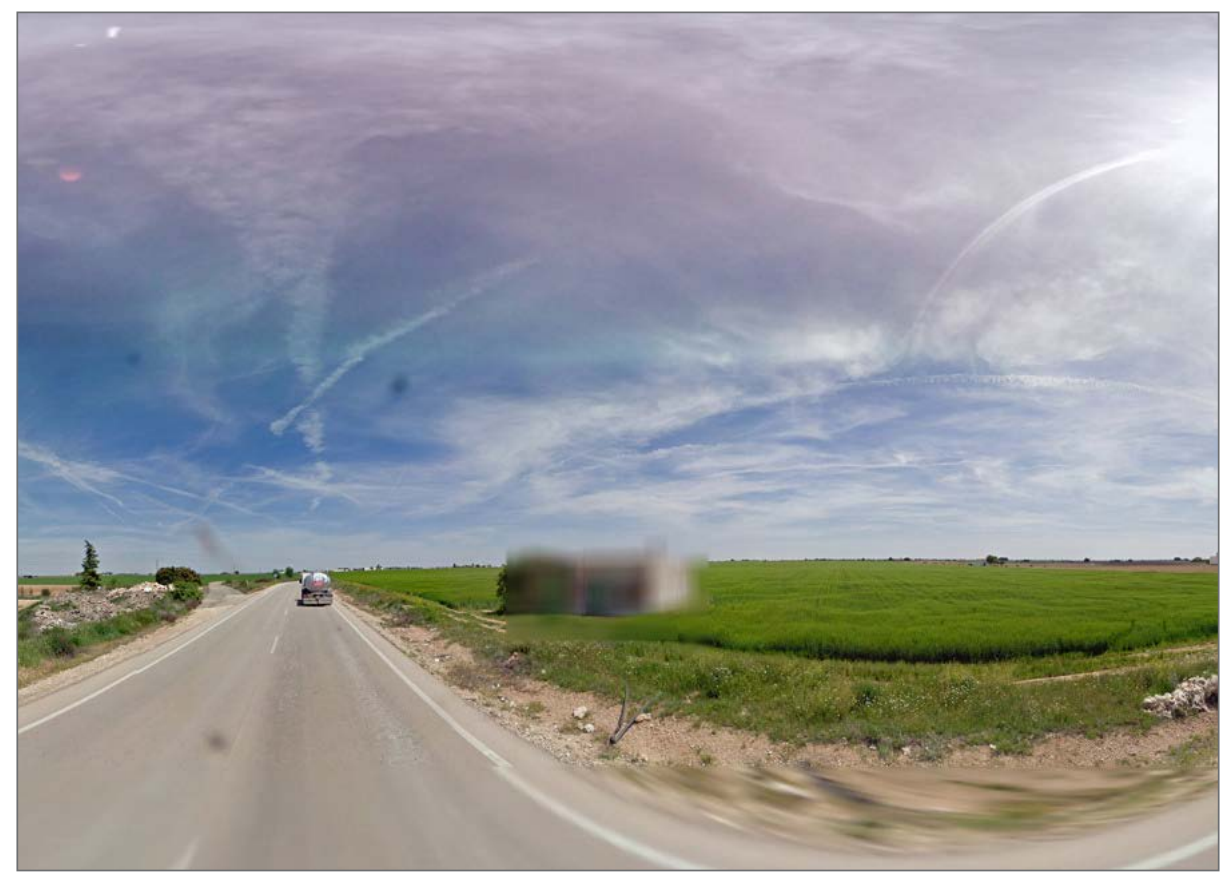

Fig. 2 http://goo.gl/maps/xcK7s, una de las intervenciones de Out of Focus en Google Street View ${ }^{10}$.

El proyecto se inició ensayando intervenciones de forma aleatoria para verificar su viabilidad, y así, una vez comprobado el procedimiento, se realizaron las peticiones. De entre todos los formularios enviados, menos de la mitad fueron desestimados por Google, mientras que el resto fueron aprobados y por lo tanto los elementos difuminados. El criterio que aplica la plataforma para aprobar o desestimar los informes no parece presentar un patrón coherente. A pesar de que las peticiones más concretas parecieron tener mayor éxito, no se puede establecer con certeza las pautas que sigue la plataforma a la hora de validar los informes.

Los elementos difuminados consisten en diversas edificaciones, como varios pisos y viviendas particulares, una casa de lujo que estaba en venta o la casa-museo de un escritor famoso; varios vehículos, como un coche que estaba siendo llevado por la grúa, un camión o una embarcación de recreo atracada en un puerto deportivo; y diferentes personas, como una persona que posa de espaldas mientras le hacen una foto, un trabajador que cuida el acceso de un hospital en obras, un hombre trajeado que sale de un palacio de congresos o una persona que espera en medio de la calzada a cruzar un 
paso de peatones. De entre todas las intervenciones se realizó una selección atendiendo a la estética, la variedad y sus posibilidades de interpretación.

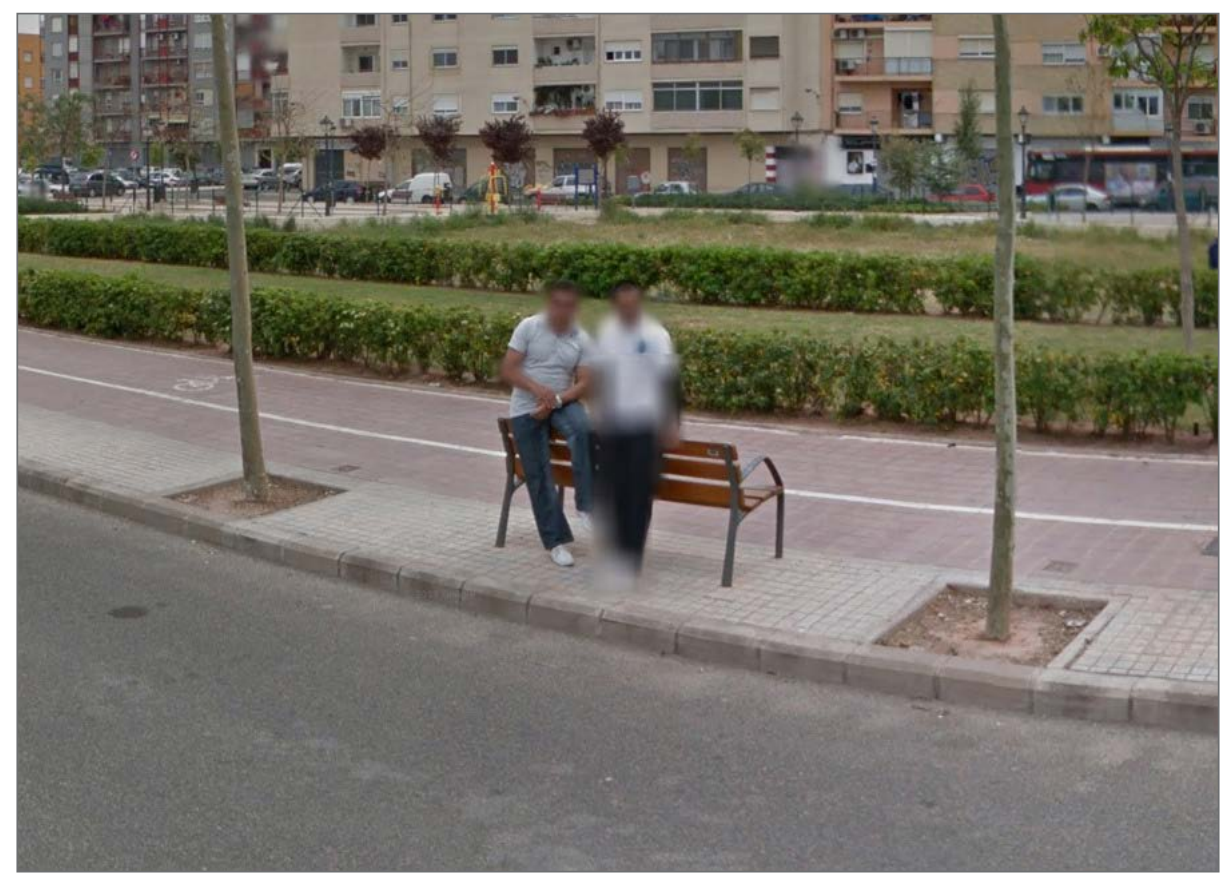

Fig.3 http://goo.gl/maps/pPIBk, una de las intervenciones de Out of Focus en Google Street View ${ }^{11 .}$

\section{LA INTERVENCIÓN COMO MICRORREVUELTA}

Y; el mapa está cerrado, pero la zona autónoma está abierta. Metafóricamente se despliega dentro de las dimensiones fractales invisibles a la cartografía del control.

(Bey 1996, 141)

A pesar de que estas pequeñas acciones no configuran, sino de manera anecdótica, el entorno virtual de Google Street View, introducen pequeñas modificaciones que de una forma simbólica interfieren en el espacio hiperreal que muestra la plataforma, añadiendo, dicho sea de paso, cierta subjetividad en una realidad excesivamente idealizada. Esta subjetividad también se produce en los mismos relatos ficticios que han servido para provocar el borrado de los 
elementos de la plataforma. Es decir, a pesar de no constituir estos relatos elementos visibles, estos quedan almacenados en las bases de datos de Google.

De alguna forma, estas pequeñas intervenciones provocan cierta atención en la exploración de Street View, es decir, no solamente se usa la plataforma como una mera consulta para ver un lugar concreto, sino que supone un uso desde una posición activa que modifica su entorno en busca de elementos que puedan aportar cierto sentido crítico o estético al 'ficcionar' la realidad que muestra. Por lo tanto, ¿no constituyen estas alteraciones del espacio virtual una forma de disidencia?

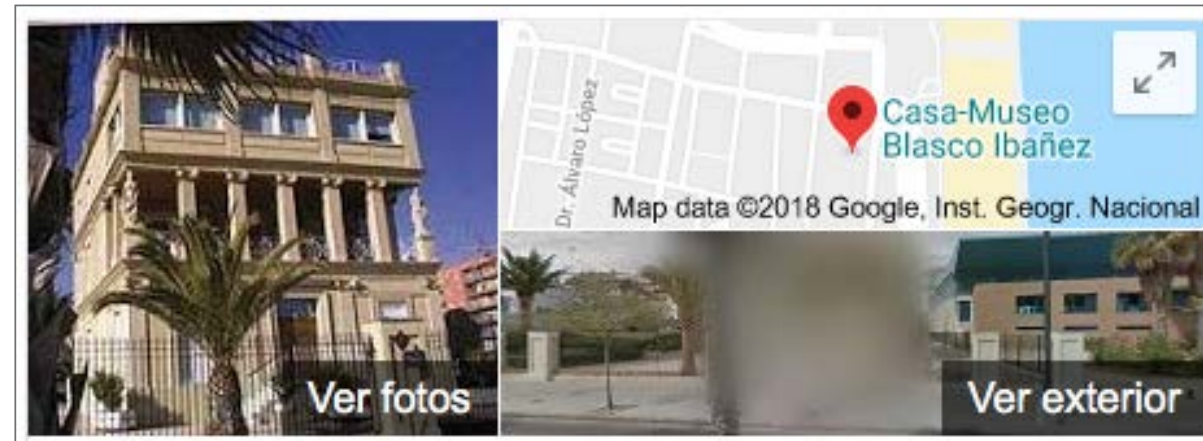

\section{Casa-Museo de Blasco lbáñez}

Sitio web Cómo llegar Guardar
$4,2 \star \star \star \star$
Museo de historia local en Valencia

La Casa-Museo Blasco lbáñez es un museo ubicado en la calle Isabel de Villena número 159 de la ciudad de Valencia. Wikipedia

Dirección: Carrer d'Isabel de Villena, 159, 46011 València

Fig.4 El resultado de búsqueda en Google de uno de los elementos intervenidos.

Hakim Bey introducía en 1991 el concepto de las "zonas temporalmente autónomas" como única manera posible de crear pequeños "enclaves libres" que escaparan a la regulación de las instancias de poder, y que emergerían mediante pequeñas revueltas. Si el mapa está hoy día, más clausurado que 
nunca, estas revueltas no pueden ser mayores que lo son las pequeñas fisuras de esta representación 1:1. Cabe plantearse si las intervenciones simbólicas hechas por prácticas artísticas como Out of Focus no son más que una evolución hacia esas dimensiones fractales de las zonas temporalmente autónomas en condiciones más adversas, en un entorno dramáticamente más controlado.

Por otro lado, la disidencia de Out of Focus entronca con la defensa del derecho a la privacidad en Internet, que se cristalizó en la sentencia europea del Tribunal de Justicia de la Unión Europea (TJUE) del 13 de mayo de 2014, y que reconoce el derecho de los ciudadanos a suprimir sus datos personales de la difusión pública en Internet bajo ciertos requisitos. Out of Focus aprovecha los mecanismos de borrado de elementos aportados por Google (que la compañía introdujo como respuesta a la progresiva presión social y judicial por la defensa de este derecho), para desplegar una estrategia de ocultación que paradójicamente evidencia la hipervisibilidad mediática. De este modo, la ocultación opera como forma de "resistencia contra la transparencia radical y la visión total a la que aspiran los gobiernos y empresas de las sociedades contemporáneas" (Dueñas Villamiel 2014, 451).

\section{CONCLUSIONES}

Tras contextualizar históricamente la evolución del Internet comercial, describir el desplazamiento de la práctica artística en Internet hacia la utilización de los servicios y tecnologías de las grandes compañías, y analizar los usos más característicos de las mismas, hemos señalado cómo algunas de estas prácticas cuestionan los mecanismos de funcionamiento de estas tecnologías y sus implicaciones sociales, centrándonos en el estudio de caso de Out of Focus. Esta obra, que interviene Google Street View mediante el borrado (desenfocado) de elementos de la misma, es un ejemplo de posible disidencia ideológica desde el arte, una disidencia puntual y localizada que se ejerce mediante la introducción de subjetividad en el espacio homogeneizado de la cartografía digital y como contestación a la aspiración de hipervisibilidad mediática de la compañía Google. 


\section{Referencias}

Bey, Hakim. 1996. La zona temporalmente autónoma. Traducción y notas de Guadalupe Sordo. Madrid: Talasa

Borges, Jorge Luis. (1935) 1987. Historia universal de la infamia. Madrid: Alianza

Brea, Jose Luis. 2007. Cultura_RAM: Mutaciones de la cultura en la era de su distribución electrónica. Barcelona: Gedisa

Careri, Francesco. 2002. Walkscapes: El andar como práctica estética. Prefacio de Giles A. Tiberghien; traducción de Maurici Plá. Barcelona: Gustavo Gili

Dueñas Villamiel, Jorge. 2014. "Del camuflaje en el arte contemporáneo a la privacidad en el net-art". Teknokultura 11 (2): 441-52

Fontcuberta, Joan. 2016. La furia de las imágenes: Notas sobre la postfotografía. Barcelona: Galaxia Gutenberg

Giannetti, Claudia. 2002."Breve balance de la primera década del net art”. Red Digital 3. http:// reddigital.cnice.mec.es/3/firmas/firmas_claudia_ind.html

Martín Prada, Juan. 2012. Prácticas artísticas e Internet en la época de las redes sociales. Madrid: Akal

Staltz, André. 2017. The web began dying in 2014, here's how. Blog personal del autor, 30 oct. https://staltz.com/the-web-began-dying-in-2014-heres-how.html

Vavarella, Emilio. 2013. Some personal thoughts on Google mapping.Web personal del autor. http://emiliovavarella.com/archive/google-trilogy/report-a-problem/

\section{Notas}

${ }^{1}$ El artista Joan Fontcuberta $(2016,184)$ compara este relato con el fenómeno de la sobreabundancia de imágenes que actualmente supera a la realidad.

${ }^{2}$ http://benkinsley.com/street-with-a-view

${ }^{3} \mathrm{http}: / / 9$-eyes.com

${ }^{4}$ http://emiliovavarella.com/archive/google-trilogy

${ }^{5} \mathrm{http}: / /$ paolocirio.net/work/street-ghosts

${ }^{6} \mathrm{http}: / /$ marionbalac.com/works/anonymous-gods

${ }^{7}$ http://mariosantamaria.net/trolling.html

${ }^{8}$ En 2013 Google Street View implementó en su sistema una herramienta que permite explorar el mismo lugar desde distintas vistas temporales que coinciden con el momento en que se realizó el registro.

${ }^{9}$ Un repositorio online de las intervenciones está disponible en http://informedeunerror.tumblr. $\mathrm{com} /$

${ }^{10}$ Esta intervención se titula http://goo.gl/maps/xcK7s, que es una dirección URL acortada que Google Street View proporciona para compartir sus ubicaciones. Debido a que este tipo de direcciones pueden ser perecederas, la URL completa en la que 
se puede consultar la intervención es: https://www.google.es/maps/@39.2462846,3.2620857,3a,75y,134.25h,81.08t/data=!3m6!1e1!3m4!1s7wKRAAvOKI35NBQi3COqug!2e0!7i13312! $8 \mathrm{i} 6656 ? \mathrm{hl}=\mathrm{es}$

${ }^{11}$ Como en la figura anterior, la URL completa de esta intervención es: https://www.google.es/ maps/@39.4992582,-0.3775476,3a,37.5y,126.34h,88.75t/data=!3m7!1e1!3m5!1s4W0qBE-LDyRQNKNJRASf6g!2e0!5s20120401T000000!7i13312!8i6656

(Artículo recibido: 11-11-18; aceptado: 23-12-18) 